\title{
Efficacy and safety of Nab-paclitaxel in breast cancer: a meta-analysis
}

\author{
Upendra Yadav, Pradeep Kumar, and Vandana Rai* \\ Human Molecular Genetics Laboratory, Department of Biotechnology, \\ VBS Purvanchal University, Jaunpur (UP)- 222 003, India \\ *Correspondence: raivandana@ rediffmail.com
}

\begin{abstract}
:
Worldwide breast cancer is the leading cause of cancer related death in women. Paclitaxel is an effective drug used for the treatment of breast cancer but it has many side effects. Nabpaclitaxel (nanoparticle albumin-bound paclitaxel) is an FDA approved drug for the treatment of breast cancer. Currently many clinical trials are conducted to deliver nab-paclitaxel into the tumor cells. But the efficacy and safety of this nab-paclitaxel over conventional paclitaxel still remains questionable. So, we performed a meta-analysis to evaluate the efficacy and safety of nab-paclitaxel in breast cancer treatment.

Electronic databases were searched for the suitable studies using key terms "nab-paclitaxel", "paclitaxel", and "clinical trial" with the combination of "breast cancer" up to August 11, 2019. Risk ratio (RR) and odds ratio (OR) with corresponding $95 \%$ confidence intervals (CIs) were calculated. All statistical analyses were performed by the Open Meta-Analyst program. A total of eight studies which fulfilled our criteria were included in this study. For efficacy we retrieved data of 12 months progression free survival, 24 months progression free survival, and overall survival (up to 3 years) and for the safety we took data of nausea, anemia, leukopenia, neutropenia, fatigue, diarrhea and pain.

We did not found any difference in efficacy of nab-paclitaxel over paclitaxel (12 months progression free survival- $\mathrm{RR}_{\mathrm{FE}}=0.86,95 \% \mathrm{CI}=0.77-0.97, \mathrm{p}=0.02, \mathrm{I}^{2}=25.07 \% ; 24$ months progression free survival- $\mathrm{RR}_{\mathrm{FE}}=0.86,95 \% \mathrm{CI}=0.64-1.16, \mathrm{p}=0.34, \mathrm{I}^{2}=0 \%$; and 3 years survival- $\left.\mathrm{RR}_{\mathrm{FE}}=1.20,95 \% \mathrm{CI}=0.92-1.56, \mathrm{p}=0.16, \mathrm{I}^{2}=37.55 \%\right)$. The meta-analysis of studies used nab-paclitaxel showed reduced adverse effect of anemia $\left(\mathrm{OR}_{\mathrm{FE}}=1.66,95 \% \mathrm{CI}=1.26\right.$ $\left.2.19 ; \mathrm{p}=<0.001 ; \mathrm{I}^{2}=0 \%\right)$ and leukopenia $\left(\mathrm{OR}_{\mathrm{FE}}=1.37 ; 95 \% \mathrm{CI}=1.06-1.75 ; \mathrm{p}=0.01 ; \mathrm{I}^{2}=\right.$ $48.63 \%)$. However, in case of other adverse effects no significant association was found with nab-paclitaxel (nausea- $\mathrm{OR}_{\mathrm{FE}}=1.15,95 \% \mathrm{CI}=0.94-1.41, \mathrm{p}=0.15, \mathrm{I}^{2}=50.12 \%$; neutropenia$\mathrm{OR}_{\mathrm{RE}}=0.75,95 \% \mathrm{CI}=0.30-1.87, \mathrm{p}=0.54, \mathrm{I}^{2}=94.45 \%$; fatigue- $\mathrm{OR}_{\mathrm{RE}}=1.11,95 \% \mathrm{CI}=0.77-$ $1.62, \mathrm{p}=0.55, \mathrm{I}^{2}=56.02$; diarrhea- $\mathrm{OR}_{\mathrm{FE}}=1.11,95 \% \mathrm{CI}=0.77-1.62, \mathrm{p}=0.55 ; \mathrm{I}^{2}=34.26$; pain$\left.\mathrm{OR}_{\mathrm{RE}}=1.15,95 \% \mathrm{CI}=0.78-1.69, \mathrm{p}=0.45, \mathrm{I}^{2}=52.96 \%\right)$.
\end{abstract}


In conclusion the use of nab-paclitaxel has reduces the side effects of anemia and leukopenia in breast cancer treatment in comparison to paclitaxel but nab-paclitaxel has no effect on the overall survival of the patients.

Keywords: Breast cancer; nanomedicine; paclitaxel, clinical trial; meta-analysis.

\section{Introduction:}

Worldwide breast cancer is the leading cause of cancer related death in women with 2,088,849 new cases and 626,679 deaths recorded in 2018 [1]. Paclitaxel is an effective antitumor taxane agent that is used against a number of cancers along with breast cancer [2]. The taxane binds to the $\beta$-subunit of the dimeric protein $\alpha, \beta$-tubulin in microtubules in a $1: 1$ molar ratio, which decreases the dynamic nature of microtubules leads to mitotic arrest and finally results in programmed cell death [3]. The paclitaxel has poor aqueous solubility, hence its commercial formulation consists of the cremophor EL (CrEL) solvent system along with ethanol. Cremophor can aggravate serious toxicities like- nephrotoxicity, neurotoxicity, hypersensitivity and even irreversible sensory neuropathy $[4,5]$. To overcome the risk of hypersensitivity reaction caused by cremophor, the CrEL requires a long infusion period along with premedication with steroids and antihistamines [6]. Even after precautions, sometime severe fatal hypersensitivity reactions still occur [7].

In 2005, Food and Drug Administration, USA approved nanoparticle albumin-bound paclitaxel (nab-paclitaxel) for breast cancer treatment. Nab-paclitaxel is cremophor-free drug. This has short infusion and has no CrEL related side effects and allergic reactions.

Various clinical trials were conducted to test effect of nab-paclitaxel in breast cancer. But the efficacy and safety of this nab-paclitaxel over conventional paclitaxel still remains questionable. So, we performed a meta-analysis to evaluate the efficacy and safety of nabpaclitaxel in breast cancer treatment.

\section{Materials and methods:}

Electronic databases (PubMed, Google Scholar, SpringerLink, ScienceDirect) were searched for the suitable studies using key terms "nab-paclitaxel", "paclitaxel", and "clinical trial" with the combination of "breast cancer" up to August 11, 2019.

\section{Inclusion and exclusion criteria:}

Eligible studies had to meet the following criteria: (i) the study should be a clinical trial, and (ii) the articles must report the sample size, number of samples of paclitaxel and nab- 
paclitaxel. The following exclusion criteria were used: (i) case-control studies; (ii) studies that contained duplicate data; (iii) no usable data reported; (iv) studies conducted on the animal model system; and (v) book chapters or reviews articles etc.

\section{Data extraction:}

The following information were extracted from all the selected articles: (i) the name of the first author; (ii) year of publication; (iii) country of study; (iv) ethnicity; and (v) distribution of number of samples in paclitaxel and nab-paclitaxel groups. For efficacy we retrieved data of 12 months progression free survival, 24 months progression free survival, and overall survival (up to 3 years) and for the safety we took data of nausea, anemia, leukopenia, neutropenia, fatigue, diarrhea and pain.

\section{Statistical analysis:}

Meta-analysis was done according to the method given in Rai et al. [8]. Pooled odds ratio $(\mathrm{OR})$ and risk ratio (RR) with its corresponding 95\% confidence interval (CI) was calculated to investigate the association between safety and efficacy of nab-paclitaxel and breast cancer risk. Heterogeneity, publication bias and subgroup analysis were done as per the method given in Rai et al. [8]. All p values are two tailed with a significance level at 0.05 and all statistical analyses were undertaken using the freely available program Open Meta-Analyst [9].

\section{Results:}

A total of eight studies [10-17] which fulfilled our criteria were included in this study. We did not found any difference in efficacy of nab-paclitaxel over paclitaxel (12 months progression free survival- $\mathrm{RR}_{\mathrm{FE}}=0.86,95 \% \mathrm{CI}=0.77-0.97, \mathrm{p}=0.02, \mathrm{I}^{2}=25.07 \% ; 24$ months progression free survival- $\mathrm{RR}_{\mathrm{FE}}=0.86,95 \% \mathrm{CI}=0.64-1.16, \mathrm{p}=0.34, \mathrm{I}^{2}=0 \%$; and 3 years survival- $\left.\mathrm{RR}_{\mathrm{FE}}=1.20,95 \% \mathrm{CI}=0.92-1.56, \mathrm{p}=0.16, \mathrm{I}^{2}=37.55 \%\right)$ (Figure 1 ).

Fig. 1. Fixed effect Forest plot of 12 months progression free survival

The meta-analysis of studies used nab-paclitaxel showed reduced adverse effect of anemia $\left(\mathrm{OR}_{\mathrm{FE}}=1.66,95 \% \mathrm{CI}=1.26-2.19 ; \mathrm{p}=<0.001 ; \mathrm{I}^{2}=0 \%\right)$ and leukopenia $\left(\mathrm{OR}_{\mathrm{FE}}=1.37 ; 95 \% \mathrm{CI}=\right.$ $1.06-1.75 ; \mathrm{p}=0.01 ; \mathrm{I}^{2}=48.63 \%$ ) (Figure 2). However, in case of other adverse effects no significant association was found with nab-paclitaxel (nausea- $\mathrm{OR}_{\mathrm{FE}}=1.15,95 \% \mathrm{CI}=0.94$ - 
1.41, $\mathrm{p}=0.15, \mathrm{I}^{2}=50.12 \%$; neutropenia- $\mathrm{OR}_{\mathrm{RE}}=0.75,95 \% \mathrm{CI}=0.30-1.87, \mathrm{p}=0.54, \mathrm{I}^{2}=$ 94.45\%; fatigue- $\mathrm{OR}_{\mathrm{RE}}=1.11,95 \% \mathrm{CI}=0.77-1.62, \mathrm{p}=0.55, \mathrm{I}^{2}=56.02$; diarrhea- $\mathrm{OR}_{\mathrm{FE}}=1.11$, $95 \% \mathrm{CI}=0.77-1.62, \mathrm{p}=0.55 ; \mathrm{I}^{2}=34.26$; pain- $\mathrm{OR}_{\mathrm{RE}}=1.15,95 \% \mathrm{CI}=0.78-1.69, \mathrm{p}=0.45, \mathrm{I}^{2}=$ $52.96 \%$ ) (Table 1).

Fig. 2. Fixed effect Forest plot of a. Anemia; b. Leukopenia

Table 1. Summary estimates for the odds ratio (OR) of various conditions, the significance level (p-value) of heterogeneity test ( $\mathrm{Q}$ test) and the $\mathrm{I}^{2}$ metric.

\begin{tabular}{r|llll} 
Condition & Fixed effect & Random effect & $\boldsymbol{I}^{2}(\boldsymbol{\%})$ & $\boldsymbol{p}(\boldsymbol{Q})$ \\
\hline Nausea & $1.15(0.94-1.41), 0.15$ & $1.29(0.85-1.97), 0.22$ & 50.12 & 0.07 \\
Anemia & $\mathbf{1 . 6 6}(\mathbf{1 . 2 6 - 2 . 1 9}),<\mathbf{0 . 0 0 1}$ & $\mathbf{1 . 6 4}(\mathbf{1 . 2 4 - 2 . 1 6}),<\mathbf{0 . 0 0 1}$ & $\mathbf{0}$ & $\mathbf{0 . 4 9}$ \\
Leukopenia & $\mathbf{1 . 3 7}(\mathbf{1 . 0 6 - 1 . 7 5}), \mathbf{0 . 0 1 3}$ & $\mathbf{1 . 2 5}(\mathbf{0 . 8 4 - 1 . 8 6}), \mathbf{0 . 2 6}$ & $\mathbf{4 8 . 6 3}$ & $\mathbf{0 . 0 6}$ \\
Neutropenia & $1.18(0.99-1.40), 0.05$ & $0.75(0.30-1.87), 0.54$ & 94.45 & $<0.001$ \\
Fatigue & $1.25(1.01-1.53), 0.03$ & $1.11(0.77-1.62), 0.55$ & 56.02 & 0.05 \\
Diarrhea & $1.15(0.95-1.39), 0.14$ & $1.01(0.74-1.39), 0.91$ & 34.26 & 0.19 \\
Pain & $1.13(0.92-1.38), 0.21$ & $1.15(0.78-1.69), 0.45$ & 52.96 & 0.07 \\
12 months progression free survival & $0.86(0.77-0.97), 0.02$ & $0.87(0.76-1.00), 0.05$ & 25.07 & 0.25 \\
24 months progression free survival & $0.86(0.64-1.16), 0.34$ & $0.87(0.65-1.16), 0.34$ & 0 & 0.42 \\
Overall survival (up to 3 years) & $1.20(0.92-1.56), 0.16$ & $1.21(0.80-1.84), 0.35$ & 37.55 & 0.20
\end{tabular}

\section{Discussion:}

This meta-analysis was designed to compare the effect of nab-paclitaxel and paclitaxel in the treatment of breast cancer. The results showed that the nab-paclitaxel reduces the adverse effects of anemia and leukopenia but failed to demonstrate survival advantages of nabpaclitaxel over paclitaxel. During literature search we found that a meta-analysis was conducted in the year 2017 on the same problem but that study demonstrated that the nabpaclitaxel has no advantage over conventional paclitaxel [18].

Nab-paclitaxel can reach higher tumor accumulation than paclitaxel, due to a receptormediated transport process [19-21] and an enhanced permeability and retention (EPR) effect [22]. Also, it exhibits promising tolerability with less side effects than sb-paclitaxel because this formulation is free of cremophor. Therefore, nab-paclitaxel has great advantages in the treatment of cancer and has attracted great attention.

Meta-analysis is a powerful tool for analyzing cumulative data with small and low power studies. During past few years this technique becomes very popular among the geneticists and epidemiologists as it provide concrete evidence for the association of certain disease/disorder 
with a particular gene or the factor. Several meta-analyses were published which evaluated risk of genetic polymorphism for different diseases and disorders like- prostate cancer [23], schizophrenia [24], Alzheimer's disease [25], digestive tract cancer [26], breast cancer [27], Down syndrome [28], esophageal cancer [29], colorectal cancer [30], prevalence of glucose 6 phosphate dehydrogenase deficiency [31], cleft lip and palate [32] or in the MTHFR C677T polymorphism prevalence [33].

The main strengths of our meta-analysis were absence of publication bias, large number of subjects, more studies than the previous meta-analysis. At the same time the present metaanalysis also has some limitations which must be acknowledged like- a) crude odds ratio and risk ratio was used, b) only clinical trials were included, and c) only chemotherapy methods were evaluated other important factors like environmental were not considered.

In conclusion, this meta-analysis demonstrated that nab-paclitaxel has reduces the side effects of anemia and leukopenia in breast cancer treatment in comparison to paclitaxel but at the same time this nab-paclitaxel has no effect on the overall survival of the patients. Finally we recommend that the nab-paclitaxel is an appropriate clinical drug that may achieve greater anticancer efficacy with generally tolerable toxicities than traditional chemotherapy.

Acknowledgments: Upendra Yadav is highly grateful to VBS Purvanchal University, Jaunpur for providing financial assistance to him in the form of PDF.

\section{References:}

1. Bray, F., Ferlay, J., Soerjomataram, I., et al.: Global Cancer Statistics 2018: GLOBOCAN Estimates of Incidence and Mortality Worldwide for 36 Cancers in 185 Countries. CA: Cancer J Clin 68, 394-424 (2018).

2. Mollinedo, F., Gajate, C.: Microtubules, microtubule-interfering agents and apoptosis. Apoptosis 8(5), 413-450 (2003).

3. Jordan, M.A.: Mechanism of Action of Antitumor Drugs that Interact with Microtubules and Tubulin. Curr Med Chem Anticancer Agents 2(1), 1-17 (2002).

4. Weiss, R.B., Donehower, R.C., Wiernik, P.H., et al.: Hypersensitivity reactions from taxol. J Clin Oncol 8, 1263-1268 (1990).

5. ten Tije, A.J., Verweij, J., Loos, W.J. et al.: Pharmacological effects of formulation vehicles: implications for cancer chemotherapy. Clin Pharmacokinet 42, 665-685 (2003).

6. Socinski, M.A.: Single-agent paclitaxel in the treatment of advanced non-small cell lung cancer. Oncologist 4, 408-416 (1999). 
7. Tan H, Hu J, Liu S. Efficacy and safety of nanoparticle albumin-bound paclitaxel in nonsmall cell lung cancer: a systematic review and meta-analysis. Artif Cells Nanomed Biotechnol 47(1), 268-277 (2019).

8. Rai, V., Yadav, U., Kumar, P., et al.: Maternal methylenetetrahydrofolate reductase C677T polymorphism and Down syndrome risk: a meta-analysis from 34 studies. Plos One 9(9), e108552 (2014).

9. Wallace, B.C., Dahabreh, I.J., Trikalinos, T.A., et al.: Closing the gap between methodologists and endusers: $\mathrm{R}$ as a computational back-end. J Stat Software 49, 1-15 (2013).

10. Gradishar, W.J., Tjulandin, S., Davidson, N., et al.: Phase III trial of nanoparticle albumin-bound paclitaxel compared with polyethylated castor oil-based paclitaxel in women with breast cancer. J Clin Oncol 23(31), 7794-7803 (2005).

11. Guan, Z.Z., Li, Q.L., Feng, F., et al.: Superior efficacy of a Cremophor-free albuminbound paclitaxel compared with solvent-based paclitaxel in Chinese patients with metastatic breast cancer. Asia Pac J Clin Oncol 5(3), 165-174 (2009).

12. Gradishar, W.J., Krasnojon, D., Cheporov, S., et al.: Phase II trial of nab-paclitaxel compared with docetaxel as first-line chemotherapy in patients with metastatic breast cancer: final analysis of overall survival. Clin Breast Cancer 12(5), 313-321 (2012).

13. Huang, L., Chen, S., Yao, L., et al.: Phase II trial of weekly nab-paclitaxel and carboplatin treatment with or without trastuzumab as nonanthracycline neoadjuvant chemotherapy for locally advanced breast cancer. Int J Nanomedicine 10, 1969-1975 (2015).

14. Rugo, H.S., Barry, W.T., Moreno-Aspitia, A., et al. Randomized Phase III Trial of Paclitaxel Once Per Week Compared With Nanoparticle Albumin-Bound Nab-Paclitaxel Once Per Week or Ixabepilone With Bevacizumab As First-Line Chemotherapy for Locally Recurrent or Metastatic Breast Cancer: CALGB 40502/NCCTG N063H (Alliance). J Clin Oncol 33(21), 2361-2369 (2015).

15. Jain, M.M., Gupte, S.U., Patil, S.G., et al. Paclitaxel injection concentrate for nanodispersion versus nab-paclitaxel in women with metastatic breast cancer: a multicenter, randomized, comparative phase II/III study. Breast Cancer Res Treat 156(1), 125-134 (2016). 16. Untch, M., Jackisch, C., Schneeweiss, A., et al. Nab-paclitaxel versus solvent-based paclitaxel in neoadjuvant chemotherapy for early breast cancer (GeparSepto-GBG 69): a randomised, phase 3 trial. Lancet Oncol 17(3), 345-356 (2016). 
17. Tamura, K., Inoue, K., Masuda, N., et al. Randomized phase II study of nab-paclitaxel as first-line chemotherapy in patients with HER2-negative metastatic breast cancer. Cancer Sci 108(5), 987-994 (2017).

18. Liu, Y., Ye, G., Yan, D., et al.: Role of nab-paclitaxel in metastatic breast cancer: a metaanalysis of randomized clinical trials. Oncotarget 8(42), 72950-72958 (2017).

19. Schnitzer, J.E., Oh, P.: Albondin-mediated capillary permeability to albumin. Differential role of receptors in endothelial transcytosis and endocytosis of native and modified albumins. J Biol Chem 269, 6072-6082 (1994).

20. Desai, N., Trieu, V., Yao, Z., et al.: Increased antitumor activity, intratumor paclitaxel concentrations, and endothelial cell transport of cremophor-free, albumin-bound paclitaxel, ABI-007, compared with cremophor-based paclitaxel. Clin Cancer Res 12, 1317-1324 (2006).

21. Li, H.H., Li, J., Wasserloos, K.J., et al.: Caveolae-dependent and -independent uptake of albumin in cultured rodent pulmonary endothelial cells. PloS One 8, e81903 (2013).

22. Matsumura, Y., Maeda, H.: A new concept for macromolecular therapeutics in cancer chemotherapy: mechanism of tumoritropic accumulation of proteins and the antitumor agent smancs. Cancer Res 46, 6387-6392 (1986).

23. Yadav, U., Kumar, P., Rai, V.: Role of MTHFR A1298C gene polymorphism in the etiology of Prostate cancer: A systematic review and updated meta-analysis. Egypt J Med Hum Genet 17, 141-148 (2016).

24. Rai, V., Yadav, U., Kumar, P., et al.: Methylenetetrahydrofolate Reductase A1298C Genetic Variant and Risk of Schizophrenia: an updated meta-analysis. Indian J Med Res 145, 437-447 (2016).

25. Rai, V.: Methylenetetrahydrofolate Reductase (MTHFR) C677T Polymorphism and Alzheimer Disease Risk: a Meta-Analysis. Mol Neurobio 54, 1173-1186 (2017).

26. Yadav, U., Kumar, P., Rai, V.: NQO1 gene C609T polymorphism (dbSNP: rs1800566) and digestive tract cancer risk: A meta-analysis. Nutr Cancer 70(4), 557-568 (2018).

27. Rai, V., Yadav, U., Kumar, P.: Impact of Catechol-O-Methyltransferase Val 158Met (rs4680) Polymorphism on Breast Cancer Susceptibility in Asian Population. Asian Pac J Cancer Prev 18(5), 1243-1250 (2017).

28. Rai, V., Yadav, U., Kumar, P.: Null association of maternal MTHFR A1298C polymorphism with Down syndrome pregnancy: An updated meta-analysis. Egypt J Med Hum Genet 18(1), 9-18 (2017). 
29. Kumar, P., Rai, V.: Methylenetetrahydrofolate reductase C677T polymorphism and risk of esophageal cancer: An updated meta-analysis. Egypt J Med Hum Genet 19(4), 273-284 (2018).

30. Rai, V.: Evaluation of the MTHFR C677T Polymorphism as a Risk Factor for Colorectal Cancer in Asian Populations. Asian Pac J Cancer Prev 16(18), 8093-8100 (2015).

31. Kumar, P., Yadav, U., Rai, V.: Prevalence of Glucose-6-phosphate dehydrogenase deficiency in India: an updated meta-analysis. Egypt J Med Hum Genet 17, 295-302 (2016).

32. Rai, V.: Strong association of C677T polymorphism of methylenetetrahydrofolate reductase gene with nosyndromic cleft lip/palate (nsCL/P). Ind J Clin Biochem 33(1), 5-15 (2018).

33. Yadav, U., Kumar, P., Gupta, S., et al.: Distribution of MTHFR C677T gene polymorphism in healthy North Indian population and an updated meta-analysis. Indian $\mathbf{J}$ Clin Biochem 32(4), 399-410 (2016). 


\section{Studies}

Tamura et al., 2017

Jain et al., 2016

Rugo et al., 2015

Gradishar et al., 2012

Guan et al., 2009
Estimate (95\% C.I.)

$1.243(0.804,1.922)$

$0.552(0.294,1.036)$

$0.806(0.648,1.003)$

$0.876(0.731,1.050)$

$0.920(0.755,1.122)$

Overall (I^2=NA , $P=0.251) \quad 0.869(0.772,0.978)$

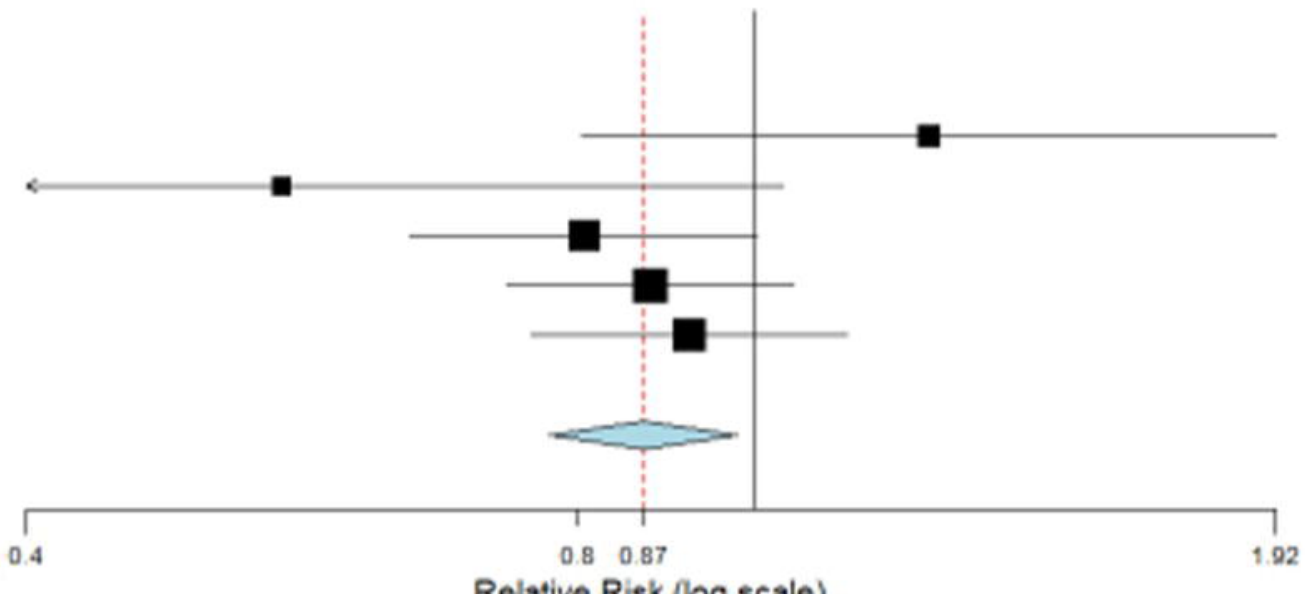

Relative Risk (log scale) 


\section{Studies}

Tamura et al., 2017

Jain et al., 2016

Untch et al., 2016

Huang et al., 2015

Guan et al., 2009
Estimate (95* C.I.)

$$
\begin{aligned}
& 1.850(1.051,3.259) \\
& 1.122(0.413,3.054) \\
& 1.721 \text { (1.165, 2.541) } \\
& 4.261(0.936,19.393) \\
& 1.099(0.523, \quad 2.312)
\end{aligned}
$$

Overall (I^2=NA , $P=0.488) \quad 1.665(1.264,2.193)$

\section{a}

Studies

Tamura et al., 2017

Jain et al., 2016

Untch et al., 2016

Huang et al., 2015

Rugo et al., 2015

Guan et al., 2009

Gradishar et al., 2005
Estimate (958 C.I.)

$0.242(0.027,2.208)$

$0.902(0.411,1.982)$

$1.384(0.895,2.140)$

$0.659(0.058,7.538)$

$2.668(1.549,4.598)$

$1.285(0.736,2.243)$

$0.786(0.369,1.675)$

Overall $\left(\left.\right|^{\wedge} 2=N A, P=0.069\right) \quad 1.370(1.069,1.756)$

b

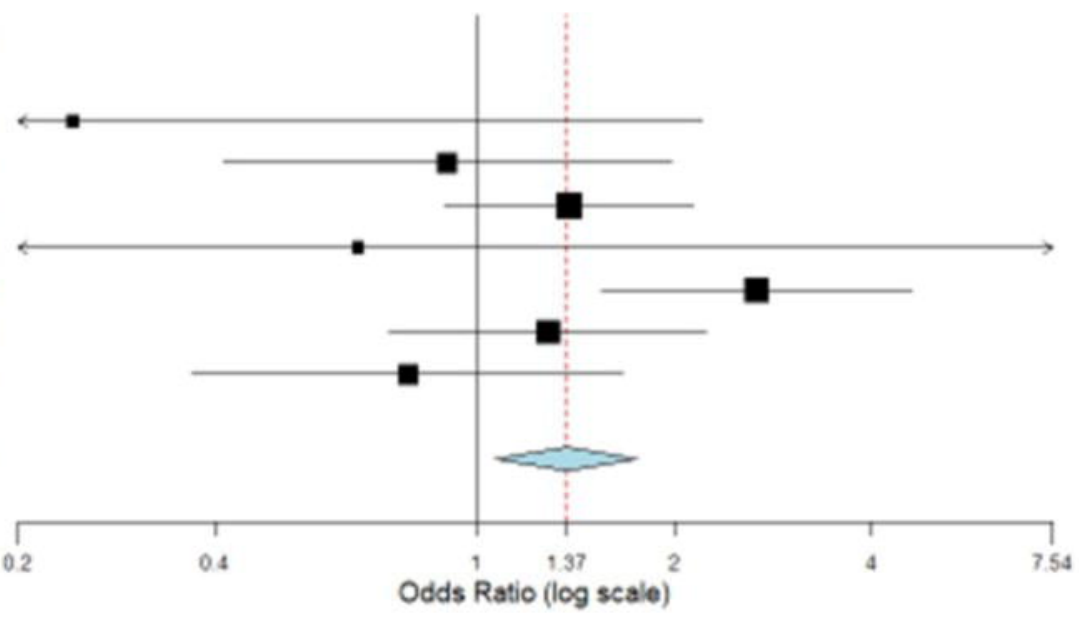

